\title{
Characterization of the cognitive impairments induced by prenatal exposure to stress in the rat
}

\author{
Julie A. Markham ${ }^{1,2 * t}$, Adam R. Taylor ${ }^{2+}$, Sara B. Taylor ${ }^{2}$, Dana B. Bell' and James I. Koenig ${ }^{1,2}$ \\ ' Department of Psychiatry, Maryland Psychiatric Research Center, University of Maryland-Baltimore School of Medicine, Baltimore, MD, USA \\ 2 Program in Neuroscience, University of Maryland-Baltimore School of Medicine, Baltimore, MD, USA
}

Edited by:

Regina M. Sullivan, Nathan Kline Institute and NYU School of Medicine, USA

\section{Reviewed by:}

Gregg Stanwood, Vanderbilt University, USA

Marie H. Monfils, University of Texas at Austin, USA

\section{*Correspondence:}

Julie A. Markham, Maryland Psychiatric Research Center, Attn: Neuroscience Program, P.O. Box 21247, Baltimore, MD, 21228, USA

e-mail:jmarkham@mprc.umaryland.edu

' Julie A. Markham and Adam R. Taylor have contributed equally to this work.
We have previously shown that male rats exposed to gestational stress exhibit phenotypes resembling what is observed in schizophrenia, including hypersensitivity to amphetamine, blunted sensory gating, disrupted social behavior, impaired stress axis regulation, and aberrant prefrontal expression of genes involved in synaptic plasticity. Maternal psychological stress during pregnancy has been associated with adverse cognitive outcomes among children, as well as an increased risk for developing schizophrenia, which is characterized by significant cognitive deficits. We sought to characterize the long-term cognitive outcome of prenatal stress using a preclinical paradigm, which is readily amenable to the development of novel therapeutic strategies. Rats exposed to repeated variable prenatal stress during the third week of gestation were evaluated using a battery of cognitive tests, including the novel object recognition task, cued and contextual fear conditioning, the Morris water maze, and iterative versions of a paradigm in which working and reference memory for both objects and spatial locations can be assessed (the "Can Test"). Prenatally stressed males were impaired relative to controls on each of these tasks, confirming the face validity of this preclinical paradigm and extending the cognitive implications of prenatal stress exposure beyond the hippocampus. Interestingly, in experiments where both sexes were included, the performance of females was found to be less affected by prenatal stress compared to that of males. This could be related to the finding that women are less vulnerable than men to schizophrenia, and merits further investigation.

Keywords: gestational stress, schizophrenia, sex differences, adolescence, animal models, cognition

\section{INTRODUCTION}

The prenatal period is a time of rapid growth and development of the brain, and perturbations to the normal series of developmental events during this time can lead to adverse functional consequences that manifest later in life. Numerous studies in both humans and rodents demonstrate that gestational stress reprograms the hypothalamic-pituitary-adrenal axis, resulting in either increased basal secretion or enhanced stress-related secretion of glucocorticoid hormones (reviewed by Weinstock, 2008). More recently an interest in the potential deleterious cognitive outcomes of prenatal stress has begun to emerge. Human infants exposed to gestational stress show poorer cognitive outcomes, as measured by the Bayley Mental Developmental Index scores (Buitelaar et al., 2003; Laplante et al., 2004; Bergman et al., 2007), an effect which appears to be mediated, at least in part, by prenatal cortisol exposure (Bergman et al., 2010; Davis and Sandman, 2010). Examination of the impact of prenatal stress on cognitive outcomes extending beyond childhood has been very limited, although one study has reported a link between maternal exposure to psychosocial stress during gestation and impaired working memory performance in young adult women (men were not examined in this study) (Entringer et al., 2009). Importantly, prenatal stress has also been implicated as a risk factor for developing schizophrenia (Khashan et al., 2008; reviewed by Koenig et al., 2002), a neuropsychiatric illness characterized by cognitive dysfunction which is untreated by currently available pharmacological therapies (Buchanan and Carpenter, 1994; Green,
1996), a situation which mandates the development of informative preclinical models for this aspect of the illness. Interestingly, the relationship between gestational stress and increased risk for schizophrenia may be stronger for men than women (van Os and Selten, 1998).

Studying the long-term neural and behavioral sequelae of prenatal stress in humans is complicated by a high degree of individual variability due in part to the confluence of a myriad of environmental factors. Animal subjects, however, can be used to establish a cleaner association between prenatal factors and postnatal outcomes, in part because environmental factors can be tightly controlled in the laboratory. To this end, the impact of prenatal stress exposure on cognition has been examined in a handful of preclinical studies. Offspring of dams that experienced repeated exposure to the same stressor during pregnancy show impairments in spatial memory (Lordi et al., 1997; Lemaire et al., 2000; Gue et al., 2004; Meunier et al., 2004; Son et al., 2006; Yang et al., 2006; Wu et al., 2007; although see Bowman et al., 2004). These studies all administered repeated exposure to the same stressor, and the majority assessed offspring prior to puberty; whether the deficits persist into adulthood is a question that is not as well investigated. Additionally, to date studies have largely interrogated hippocampal-dependent memory functions. A broader investigation is warranted, especially since prefrontal cortical dysfunction is a hallmark of schizophrenia (Goldman-Rakic, 1994), risk for which has been associated with prenatal stress. 
Our laboratory utilizes a repeated variable prenatal stress paradigm in which pregnant rat dams are subjected to a randomized series of stressors during the final week of gestation, which precludes the possibility of habituation to a single stressor. We have previously shown that male rats exposed to gestational stress exhibit phenotypes resembling what is observed in schizophrenia, including hypersensitivity to amphetamine, blunted sensory gating, disrupted social behavior, impaired stress axis regulation, and aberrant prefrontal expression of genes involved in synaptic plasticity (Kinnunen et al., 2003; Koenig et al., 2005; Lee et al., 2007). Here we employed a battery of cognitive tests, including novel object recognition, Morris water maze, fear conditioning, and iterative versions of the "Can Test," in which working and reference memory for both objects and spatial locations can be assessed, in order to obtain a more comprehensive determination of the long-term impact of prenatal stress on cognitive faculties. Additionally, female subjects were included to determine whether a sex difference exists in the cognitive vulnerability to a prenatal stress insult.

\section{MATERIALS AND METHODS}

For all experiments, timed pregnant Sprague-Dawley female rats were purchased from Charles River Laboratories and arrived at our animal facility on day 2 of gestation. All pregnant animals were housed individually in a light-controlled (lights on 07:00 hours to 19:00 hours) and temperature-controlled facility, and all dams had free access to rat chow (Harlan Teklad) and water. Half of the dams were exposed to prenatal stress according to the procedure described below, while the other (control) dams were not. All procedures described herein conform to guidelines for animal research established by the National Institutes of Health, and were approved by the University of Maryland - Baltimore School of Medicine Institutional Animal Care and Use Committee.

Beginning on day 14 and continuing through day 21 of gestation, pregnant dams were exposed to a repeated variable stress paradigm (Kinnunen et al., 2003; Koenig et al., 2005; Lee et al., 2007). Briefly, the stresses used in this paradigm were: (1) restraint in a well-ventilated cylindrical plexiglas restrainer (Harvard Bioscience, Boston, MA, USA) for $1 \mathrm{~h},(2)$ exposure to a cold environment $\left(4^{\circ} \mathrm{C}\right)$ for $6 \mathrm{~h},(3)$ overnight food deprivation, (4) prevention of sleep during the light (inactive) portion of the cycle for $90 \mathrm{~min}$, (5) $15 \mathrm{~min}$ of swim stress, and (6) social stress induced by overcrowded housing conditions during the dark (active) phase of the cycle. Two to three stressors were administered per day in a randomized order (Kinnunen et al., 2003; Koenig et al., 2005; Lee et al., 2007). All dams delivered their pups vaginally. Following delivery, the dam and her pups were left undisturbed in their cages until weaning on postnatal day 24-25. Repeated variable prenatal stress does not impact litter size or sex ratio (Lee et al., 2007). At weaning, male and female offspring were housed in same-sex, like-treated groups of two to three with free access to rat chow and water. The pups were exposed to normal animal husbandry procedures from that point forward until experimental use. Each animal was used in a single behavioral experiment. Only one animal per sex/age/treatment group was included from each litter, as is appropriate for studies of prenatal treatment effects (Holson and Pearce, 1992).

\section{OBJECT RECOGNITION MEMORY Animals}

The following eight groups of animals were included in this experiment: adolescent (day 35) and adult (day 56) males and females, of both prenatal stress and control conditions, with 10-11 animals per sex/age/prenatal stress condition for a total of 84 animals.

\section{Novel object recognition task}

Five days prior to testing, all animals were moved from the vivarium to the behavioral testing room. For three consecutive days, animals were handled for 1-2 min each. On the mornings of days four and five, animals were habituated to the empty testing apparatus for 10 min each day (i.e., no objects were placed in arena). The testing arena was a $62 \mathrm{~cm} \times 62 \mathrm{~cm} \times 46 \mathrm{~cm}$ box with black plexiglas walls. The floor of the arena was covered with unscented cat litter to allow for easy removal of urine and feces between each animal. On the morning of the sixth day the animals were assessed for novel object recognition memory, a task that evaluates whether an animal is able to differentiate between a novel object and a familiar object after an initial exposure to the familiar object.

On the day of testing, two identical objects were placed in the arena equidistant from each other and the arena walls. The animal was then placed in the arena and allowed to explore the objects for 5 min ("introduction" phase). The animal was then removed from the arena and placed in its home cage for two hours. Following the delay, the animal was reintroduced to the testing arena, which now contained one familiar object (identical to those used in the introduction) and one novel object. The behavior of the animals was scored for 30 s during this "recognition" phase, and the measure of memory was the amount of time spent investigating the novel object divided by the total time spent investigating both objects, multiplied by 100 (i.e., time novel/time total) $\times 100$ ). A score significantly greater than chance was considered indicative of memory. Between test phases and animals, soiled litter was removed from the arena and all objects were thoroughly cleansed with $70 \%$ ethanol. During both habituation trials and testing, testing order was counterbalanced for sex/age/prenatal stress condition. Locomotor activity and object investigation behavior were recorded using a camera mounted above the testing apparatus and analyzed using ANY-maze behavioral tracking software (version 4.6, Stoelting).

\section{SPATIAL MEMORY Animals}

Male Sprague-Dawley rats of both prenatal stress and control conditions (age 70 days) were included in this experiment. At the conclusion of testing, Grubbs' test for outliers identified one control animal as an outlier and this animal was excluded from further analyses. The final sample size was 15 animals ( $n=7$ control, $n=8$ prenatal stress).

\section{Morris water maze}

Behavioral testing was conducted between 09:00 and 15:00 each day. Prior to training, animals were habituated to the testing apparatus, which consisted of a circular tank, $1.8 \mathrm{~m}$ in diameter with a depth of $0.9 \mathrm{~m}$ (water depth $0.6 \mathrm{~m}$ ). The tank was located in a room with spatial cues external to the maze, including colored objects and posters hanging from the ceiling or taped to the walls. Animals 
were habituated to the testing apparatus over 2 days. On the first day, each animal was placed in the tank and allowed to explore it by swimming for $2 \mathrm{~min}$, after which time it was towel dried and returned to its home cage. The following day the rats were exposed for $2 \mathrm{~min}$ to the testing apparatus which now contained an escape platform (four exposures). For training trials, the tank water was made opaque by adding non-toxic white tempura paint, and a stable plexiglas escape platform $(13.5 \mathrm{~cm} \times 13.5 \mathrm{~cm})$ was submerged $2 \mathrm{~cm}$ below the water surface in the northwest (NW) quadrant of the maze. Training consisted of four trials per day with a 15-min inter-trial interval, and continued for three consecutive days. For each trial, the animal was placed in the maze for $2 \mathrm{~min}$, or until the escape platform was located. If after $2 \mathrm{~min}$ the animal had not located the escape platform, it was guided to it by the experimenter. Animals remained on the platform for $15 \mathrm{~s}$, after which time they were towel dried and returned to their home cage. There were three start locations (NE, SW, SE) and start location was randomized across groups/trials. Following four consecutive days on which no handling or behavioral training occurred, animals were returned to the maze for two "retention" trials (conducted in the same way as the training trials). For both training and retention trials, latency to reach the platform was recorded, and an average latency per day was determined for each animal.

\section{FEAR CONDITIONING}

\section{Animals}

Male and female Sprague-Dawley rats (age 70-95 days) of both prenatal stress and control conditions were included in this experiment, with 8-12 animals per sex/prenatal stress condition for a total of 38 animals.

\section{Fear conditioning}

An automated fear conditioning system (Coulbourn Instruments, Whitehall, PA, USA) running under the guidance of FreezeFrame software (Coulbourn Instruments) was used to evaluate fear conditioning behavior. Behavioral testing took place in $25.4 \mathrm{~cm} \times 25.4 \mathrm{~cm} \times 19.05 \mathrm{~cm}$ chambers contained in soundattenuated cubicles equipped with a speaker for delivering tones, a ventilation fan for background noise (continuously present throughout the experiment at $60 \mathrm{~dB}$ ), a house light (continuously present throughout the experiment), and a removable stainless steel grid floor for equally distributed delivery of a mild footshock, controlled via a shocker-scrambler unit automated by the FreezeFrame software (Coulbourn Instruments). The percent time spent freezing was monitored by a videotracking system driven by the FreezeFrame software. Freezing was defined as two consecutive seconds of complete movement cessation, with the exception of respiration. Immobility was automatically determined by the software; however, as indicated by the manufacturer, the software may erroneously score immobility if movement is in the vertical direction. Because animals occasionally jump in response to the footshock, an experimenter (who was blind to the animal's condition) viewed each video and, if the software had erroneously scored freezing in this way, manually adjusted the threshold to exclude this event. Each footshock grid was calibrated before each conditioning session using a digital meter to ensure that the current administered was consistent across animals. Animals received no habituation to the testing chamber prior to behavioral testing; they were moved to the testing room $30 \mathrm{~min}$ prior to testing each day, and were returned to the vivarium at the conclusion of testing each day.

On the morning of the first day, animals underwent fear conditioning, during which time an auditory stimulus was paired with a mild footshock. Following a $60 \mathrm{~s}$ acclimation period upon introduction to the chamber, the animal was presented with a tone $(90 \mathrm{~dB}$, lasting $10 \mathrm{~s})$ that co-terminated with a footshock $(1.0 \mathrm{~mA}$, lasting $1 \mathrm{~s})$. Freezing behavior was measured during the tone presentation. In total, four tone-shock pairings were presented, with each pairing separated by an inter-trial interval that lasted between 60 and $90 \mathrm{~s}$. After the final pairing, the animal remained in the chamber for $60 \mathrm{~s}$ and was then returned to its home cage. The entire trial including acclimation lasted $6.5 \mathrm{~min}$. The chamber walls and floor grid were cleaned with $95 \%$ ethanol and the drip pan beneath the floor grid was washed with detergent and cleaned with 95\% ethanol between each animal.

\section{Cued and Contextual Fear Memory Testing}

Beginning $24 \mathrm{~h}$ following fear conditioning, the animal was returned to the chamber to evaluate memory for the context in which the toneshock pairings took place (context extinction). No tones or shocks were delivered during context extinction trials, and freezing behavior was measured in response to the context in which fear conditioning took place alone. Freezing behavior was assessed for two continuous seconds beginning every $8 \mathrm{~s}$ for a period of $5 \mathrm{~min}$, and an estimated percent time spent freezing was calculated from these measures. At the conclusion of the trial, the animal was returned to its home cage. The chamber walls and floor grid were cleaned with 95\% ethanol, and the drip pan beneath the floor was washed with detergent and cleaned with 95\% ethanol between each animal. Two hours following each context extinction trial, the animal was returned to the chamber for a cue extinction trial, for which multiple contextual features of the chamber were altered (relative to conditioning and context extinction trials), namely: (1) an opaque plexiglas insert was laid over the grid floor, (2) the chamber walls and floor were cleaned with orange-scented cleaner (instead of ethanol) between animals, (3) the chamber cue light was left on for the entire trial, providing more ambient light in the chamber, (4) the door to the sound-proof chamber was left cracked open, (5) animals remained in an adjoining room (instead of the actual testing room) during periods of group testing and were transported between home cage and testing chamber using an empty holding cage, and (6) the testing chamber was switched on a per-animal basis between conditioning/context extinction trials and cue extinction trials. Therefore, multiple tactile, olfactory, visual, and other contextual cues were altered between conditioning/context extinction trials and cue extinction trials. During each 8-min cue extinction trial, no footshocks were delivered and freezing behavior in response to presentation of the tone alone was measured; these trials are an opportunity for the animal to learn that the tone no longer predicts a shock. In total, the tone $(90 \mathrm{~dB}$, lasting $10 \mathrm{~s}$ ) was presented five times per cue extinction trial, separated by an inter-trial interval that lasted between 60 and $90 \mathrm{~s}$. After the final tone presentation, the animal remained in the chamber for $60 \mathrm{~s}$ and was then returned to its home cage. There were two sets of context extinction and cue extinction trials, occurring $24 \mathrm{~h}$ and 4 days (96 h) after the initial conditioning training trial. 


\section{DISCRIMINATION MEMORY Animals}

Adult male Sprague-Dawley rats (60-90 days at the beginning of behavioral testing) of both prenatal stress and control conditions were included in this experiment. Animals underwent behavioral testing during either the light/inactive phase (experiments performed between 09:00 and 15:00) or dark/active phase (experiments performed between approximately 17:00 and 03:00; testing room was illuminated with a red light). This resulted in the following groups: control ( $n=5$ inactive, $n=7$ active) and PS ( $n=7$ inactive, $n=7$ active).

\section{Can test}

Habituation. The Can Test was first described by Popovic et al. (2001) and behavioral testing procedures described here were based off that paradigm. For five consecutive days, animals were handled for 1-2 min each; on the third day, animals were moved from the vivarium to the behavioral testing room. Three consecutive days of habituation to the testing apparatus followed the 5 days of handling. On the first day of habituation each animal was allowed $20 \mathrm{~min}$ exploration of the behavioral testing apparatus, which consisted of a $100 \mathrm{~cm} \times 100 \mathrm{~cm} \times 46 \mathrm{~cm}$ box with black plexiglas walls. Animals were returned to the home cage without access to a water bottle, in order to facilitate motivation for finding the water reward during subsequent testing. On the second habituation day, seven identically patterned aluminum cans (filled with cement for weight, $13 \mathrm{~cm}$ in height) were placed in the apparatus in a fan arrangement so as to be equidistant from the starting point. The cans were placed upsidedown, in order to provide a smooth dish to contain a small bolus of water $(0.3 \mathrm{ml})$. Water was placed in each of the cans and each animal was allowed to explore the apparatus (with water-containing cans) for $20 \mathrm{~min}$. On the third habituation day, the apparatus was set up as above, except with only three water-baited cans, and the animal was allowed to explore the apparatus until it found all three water rewards, or until $10 \mathrm{~min}$ had elapsed. Following consumption of the final reward, the animal was removed to a holding area while three new cans were baited. The animal was then reintroduced to the apparatus and again allowed to explore until finding the three rewards, or until $10 \mathrm{~min}$ had elapsed. Following the 3 days of habituation, animals were left undisturbed for 2 days. Water was again removed from the cages the day before testing began (see below). After habituation and testing, rats were allowed access to water for a 45 -min period.

Spatial/visual discrimination test. Seven cans were arranged in the apparatus with the exception that one can was covered in white tape with a design of three black horizontal lines showing. Animals were allowed ten trials per day over a 5-day period to learn that the water reward was always to be found in the unique can, the location of which remained stationary. Thus it was possible for animals to use either spatial or visual cues (or a combination) to learn the location of the water reward. Following consumption of the reward, the animal was removed to a holding area while the can was re-baited for the next trial. A correct trial was recorded when the animal visited the rewarded can first. A reference memory error was scored the first time the animal visited a non-rewarded can prior to visiting the rewarded one. A working memory error was scored each time an animal revisited the same non-rewarded can during a given trial. Average correct trials, reference memory errors, and working memory errors were calculated on a per animal basis for each day of training. Following 5 days of training, animals were returned to the vivarium for 2 weeks, after which time they were again moved to the behavioral testing room and water-restricted. Twenty-four hours later, retention memory was tested over ten trials (2-week retention test).

Spatial discrimination test. Spatial discrimination testing began 2 days following the retention memory test for spatial/object discrimination (above). For this test, the testing apparatus was arranged as above, but this time with seven identical cans, thus eliminating the visual pattern cues. Animals were allowed ten trials per day over a 5-day period to learn that the water reward was always in the same spatial location. Following consumption of the reward, the animal was removed to a holding area while the can was re-baited for the next trial. Correct trials, reference, and working memory errors were scored as above. Following five days of training, animals were returned to the vivarium for 2 weeks, after which time they were again moved to the behavioral testing room and water-restricted. Twenty-four hours later, retention memory was tested over ten trials (2-week retention test).

Visual discrimination test. Visual discrimination testing began 2 days following the retention memory test for spatial discrimination (above). For this test, the cans were arranged similar to the spatial/visual discrimination test, with one can again covered in white tape with a design of three black horizontal lines showing. This can was again consistently rewarded; however, from trial to trial its location varied. Animals were allowed ten trials per day over a 5-day period to learn that the water reward was always to be found in the visually unique can, regardless of its spatial location. Following consumption of the reward, the animal was removed to a holding area while the can was re-baited and moved for the next trial. Correct trials, reference, and working memory errors were scored as above. Following 5 days of training, animals were returned to the vivarium for 2 weeks, after which time they were again moved to the behavioral testing room and water-restricted. Twenty-four hours later, retention memory was tested over ten trials (2-week retention test). Following the 2 -week post-training retention task, animals were returned to the vivarium and left undisturbed for a 2-month period, after which time they were again moved to the behavioral testing room for a final retention test of ten trials (2-month retention test).

\section{STATISTICAL METHODS}

All statistical analyses were conducted using SPSS statistical package. For behavioral tests involving multiple trials/days per animal, analyses of variance (ANOVA) were conducted in which trial/day was included as a repeated measures factor. Post hoc tests, conducted using l-matrix contrast statements in SPSS, were used to follow up any significant main effects or interactions. The Wilcoxon signed ranks test was used to determine whether an average group score significantly differed from chance $(50 \%)$ on the recognition phase of the object recognition memory task. In order to correlate the number of working memory errors committed during training 
and number of correct trials on the subsequent 2-week retention test of the spatial/visual discrimination version of the Can Test, a Pearson product-moment correlation was calculated. For all statistical analyses, $p<0.05$ was considered significant.

\section{RESULTS}

\section{OBJECT RECOGNITION MEMORY}

$2 \times 2 \times 2 \times 2$ repeated measures analyses of variance (ANOVA) (age [adolescent vs. adult] $\times$ sex [male vs. female] $\times$ prenatal stress treatment [prenatal stress vs. control] $\times$ habituation exposure [first vs. second]) were conducted on indices of locomotor activity during the habituation trials, with habituation day included as the repeated measure. These analyses revealed the expected findings of reduced locomotor activity as a function of repeated exposure to the testing arena; distance traveled during the second habituation exposure was less than during the first $\left(F_{1,76}=142.4, p<0.01 \times 10^{-16}\right)$ (Figure 1A), and animals engaged in slightly fewer mobile episodes during the second, compared to the first, exposure $\left(F_{1,76}=5.1\right.$, $p<0.03$ ) (Figure 1B). Overall, prenatally stressed animals were more active (i.e., traveled greater distance) than control animals $\left(F_{1,76}=9.4, p<0.01\right)$ (Figure 1A). Prenatal stress did not impact the number of mobile episodes or the time spent mobile during habituation trials (Figures 1B,C); therefore, the greater distance traveled by prenatally stressed animals was due to a true increase in locomotor speed. Prenatal stress treatment, age, and habituation exposure also interacted to influence distance traveled $\left(F_{1,76}=7.9\right.$, $p<0.01)$, primarily due to the fact that the reduced activity of adults relative to adolescents was evident on exposure 1 for control animals, but for prenatally stressed animals this effect was more evident on exposure 2 (Figure 1A). Males and females did not differ on distance traveled, time spent mobile, or number of mobile episodes during habituation trials, nor did sex interact with any other factor to impact these measures. Adolescent and adult animals did differ on these measures, however. Adolescent animals spent less time mobile than did adults $\left(F_{1,76}=6.7, p<0.02\right)$, but this effect was only present on the first habituation exposure (age $\times$ habituation exposure $F_{1,76}=6.9, p<0.01$ ) (Figure 1C). Despite spending less overall time mobile, adolescents engaged in more mobile episodes than adults $\left(F_{1,76}=25.9, p<0.00001\right)$, indicating more frequent, shorter bouts of activity for younger animals. This effect was significant for both exposures but was especially pronounced on the first (age $\times$ habituation exposure $F_{1,76}=5.6, p<0.02$ ) (Figure 1B).

During the introduction phase, when animals were presented with two identical objects, different information collection styles were observed. $2 \times 2 \times 2$ ANOVAs were run to determine the impact of age, sex, and prenatal stress treatment on the number of investigatory bouts animals engaged in with the objects as well as the total time spent investigating the objects during the introduction phase. Adolescents initiated fewer investigatory bouts than adults $\left(F_{1,76}=11.7, p<0.001\right)$, and females initiated fewer investigatory bouts than males $\left(F_{1,76}=4.7, p<0.04\right)$ (Figure 2A). Females also spent less total time investigating objects during the introduction phase $\left(F_{1,76}=5.7, p<0.02\right)$; adolescents and adults did not differ on this measure (Figure 2B). Prenatal stress did not impact either of these measures, indicating that any subsequent impact on memory was not due to a difference in how much time animals spent investigating objects or how often they did so.

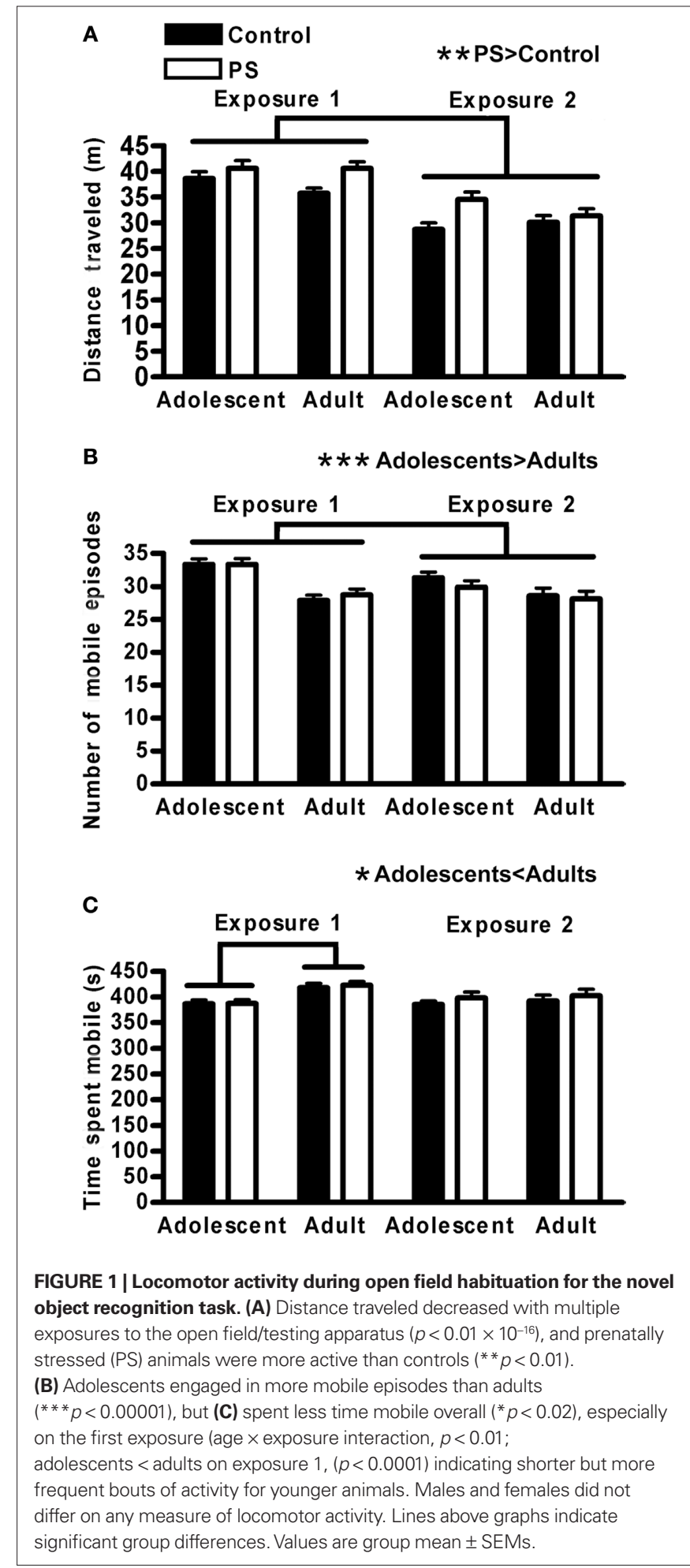

Object recognition memory during the recognition phase of the test was analyzed using the Wilcoxon signed ranks test, which determined whether an average group score was significantly greater than chance $(50 \%)$. Prior to puberty, neither prenatally stressed nor control animals of either sex demonstrated significant memory for the familiar object (all groups $p>0.1$ ). As adults, control males 
$(p<0.01)$ and control females $(p<0.066)$ demonstrated object recognition memory (Figure 2C). Prenatal stress did not impact the ability of females to develop competence on this task (prenatally stressed adult females $p<0.01$ ); however, the performance of prenatal stressed males was impaired and did not differ from chance, even as adults (prenatally stressed adult males $p>0.7$ ) (Figure 2C).

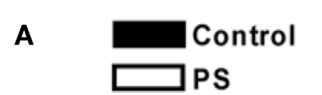

$\square$ PS
Adolescents

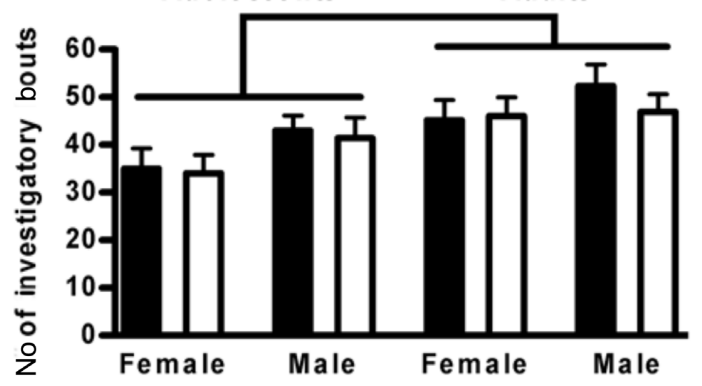

B

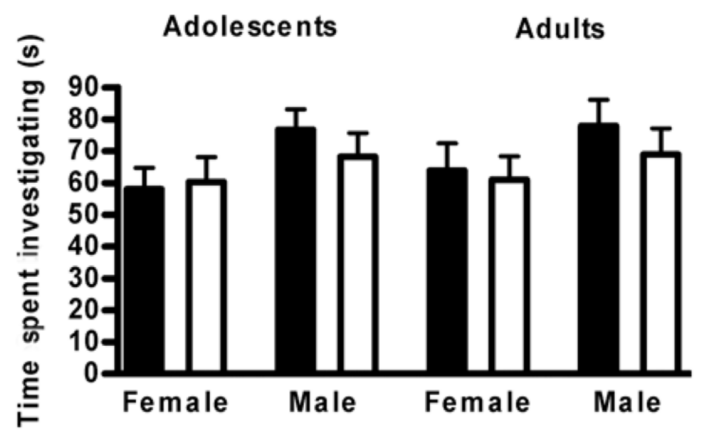

C

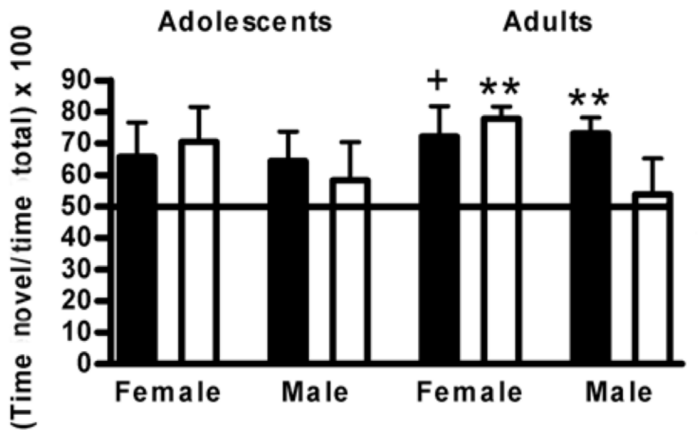

FIGURE 2 | Novel object recognition. (A) During the introduction phase, adolescents initiated fewer investigatory bouts with the objects compared to adults $(p<0.0001)$ and females engaged in fewer investigatory bouts than males ( $\left.{ }^{*} p<0.04\right)$. (B) Females also spent less time overall investigating the objects during the introduction than males $\left({ }^{*} p<0.02\right)$. (C) Object recognition memory matured over the periadolescent time frame; adolescents were not competent on this task whereas adult control males $\left({ }^{* *} p<0.01\right)$ and control females $(+p<0.066)$ performed above chance. Prenatally stressed (PS) males failed to gain competence on this task ( $p>0.7)$, whereas PS females were unaffected $\left({ }^{*} p<0.01\right)$. Lines above graphs indicate significant group differences. Values are group mean \pm SEMs.

\section{MORRIS WATER MAZE}

The time required to discover the escape platform on the second day of habituation did not differ between groups (controls $51.1 \pm 11.3$ s, prenatally stressed $56.8 \pm 12.14$ s, group mean \pm S.E.M.) A $2 \times 3$ repeated measures ANOVA was conducted to determine the influence of treatment (control, prenatal stress) and training day on latency to reach the escape platform during the 3 days of training. As expected, latency to find the platform was reduced with increasing days of training $\left(F_{2,26}=7.1, p<0.01\right)$ (Figure 3A). While the performance of prenatally stressed and control animals was equivalent at the outset of testing (trial 1, day 1 comparison $p=0.58$; group means: prenatally stressed $41.6 \pm 10.8 \mathrm{~s}$, control $32.7 \pm 11.2 \mathrm{~s}$ ), prenatal stress impaired learning on this task. Prenatally stressed animals took significantly longer to find the hidden platform compared to control animals $\left(F_{1,13}=5.7, p<0.04\right)$. For the retention test, planned paired $t$-tests were used to compare within-group performance between the final day of training and the retention test day, to evaluate whether there was any degradation of memory during the intervening time. Whereas control animals maintained the same high level of performance between the conclusion of training and the retention test day, prenatally stressed animals took longer to find the platform on the retention test day than they had on the final day of training $(t=2.4$, $p=0.05)$ (Figure 3B).
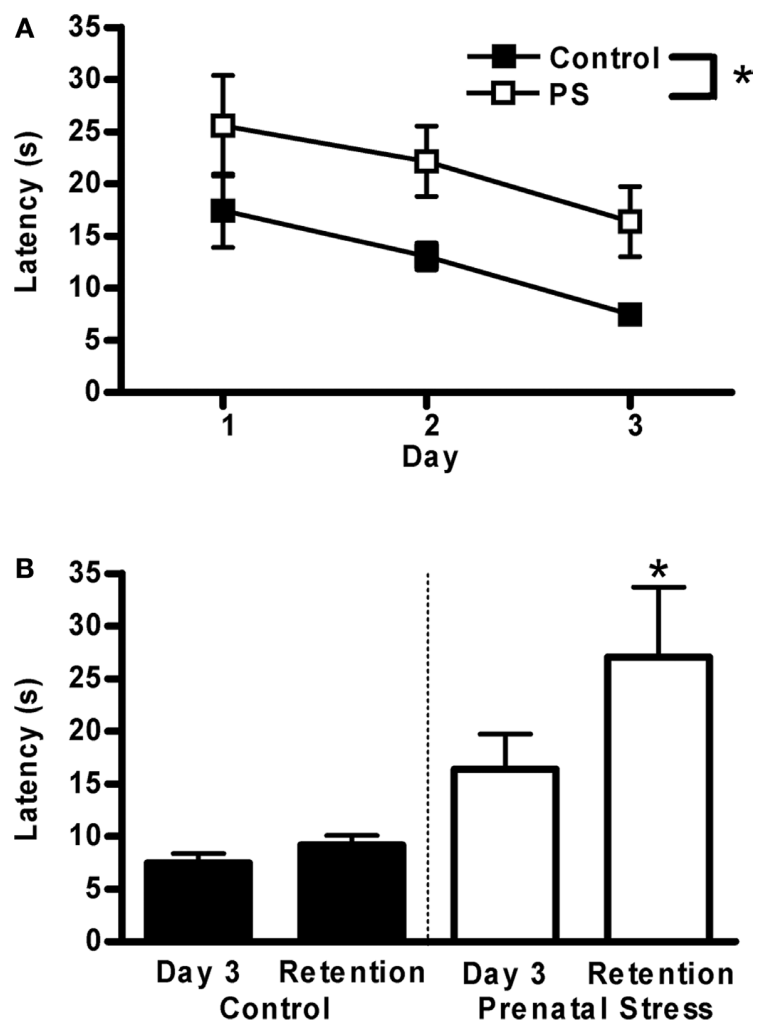

FIGURE 3 | Morris water maze. (A) Prenatally stressed (PS) male rats took significantly longer to locate a hidden platform over 3 days of training $\left({ }^{*} p<0.04\right)$. (B) On a memory retention test 4 days following training, control rats maintained their level of performance, whereas $P S$ rats did not (retention $>$ day 3 training latency, ${ }^{*} p=0.05$ ). Values are group mean $\pm \mathrm{SEM}$. 


\section{FEAR CONDITIONING}

$2 \times 2$ ANOVAs (treatment $\times$ sex) were conducted for percent freezing during fear conditioning, $24 \mathrm{~h}$, and $96 \mathrm{~h}$ extinction trials (both cue and context). During conditioning, prenatally stressed animals froze less than control animals $\left(F_{1,34}=4.3, p<0.05\right)$, and there was a trend for males to freeze less than females $\left(F_{1,34}=4.0, p<0.054\right)$ (Figures 4A,B). For cue extinction trials (Figures 4A,B), there were no main effects of either treatment or sex, but there was a significant interaction of these factors at the $96 \mathrm{~h}$ cue extinction trial $\left(F_{1,34}=5.4\right.$, $p<0.03$ ) (Figure 4C). Post hoc analyses revealed a trend for prenatally stressed males to spend more time freezing during this trial compared to control males $(p<0.09)$, whereas there was no such trend among females; in fact, the direction of the group means was opposite that of males. Additionally, a robust sex difference existed among control
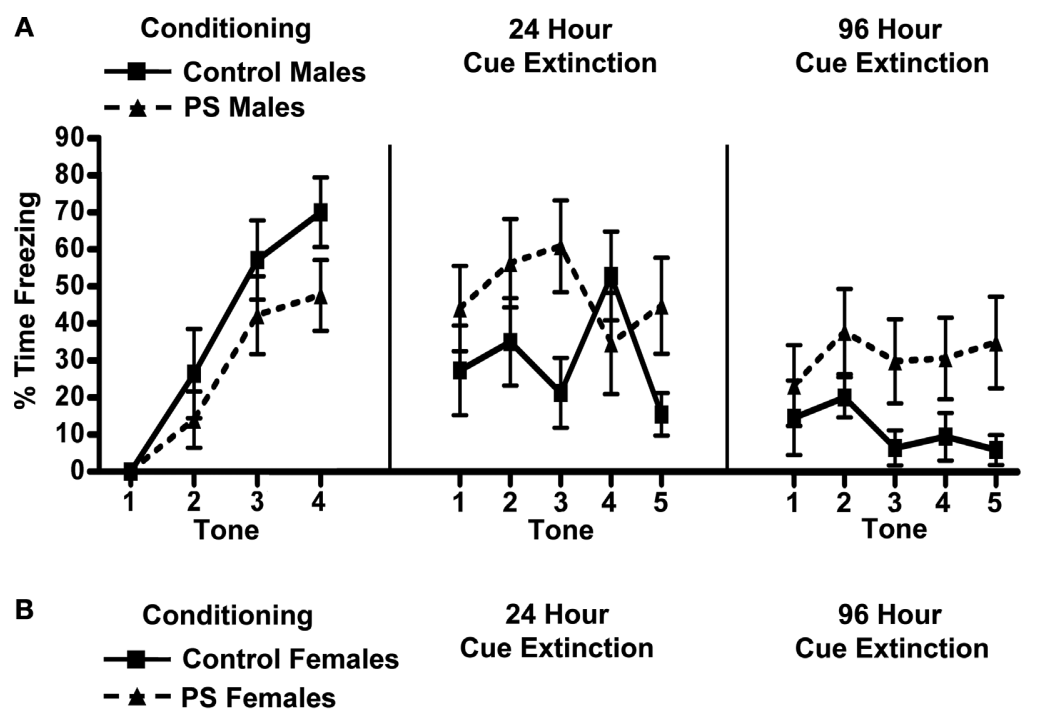

96 Hour
Cue Extinction
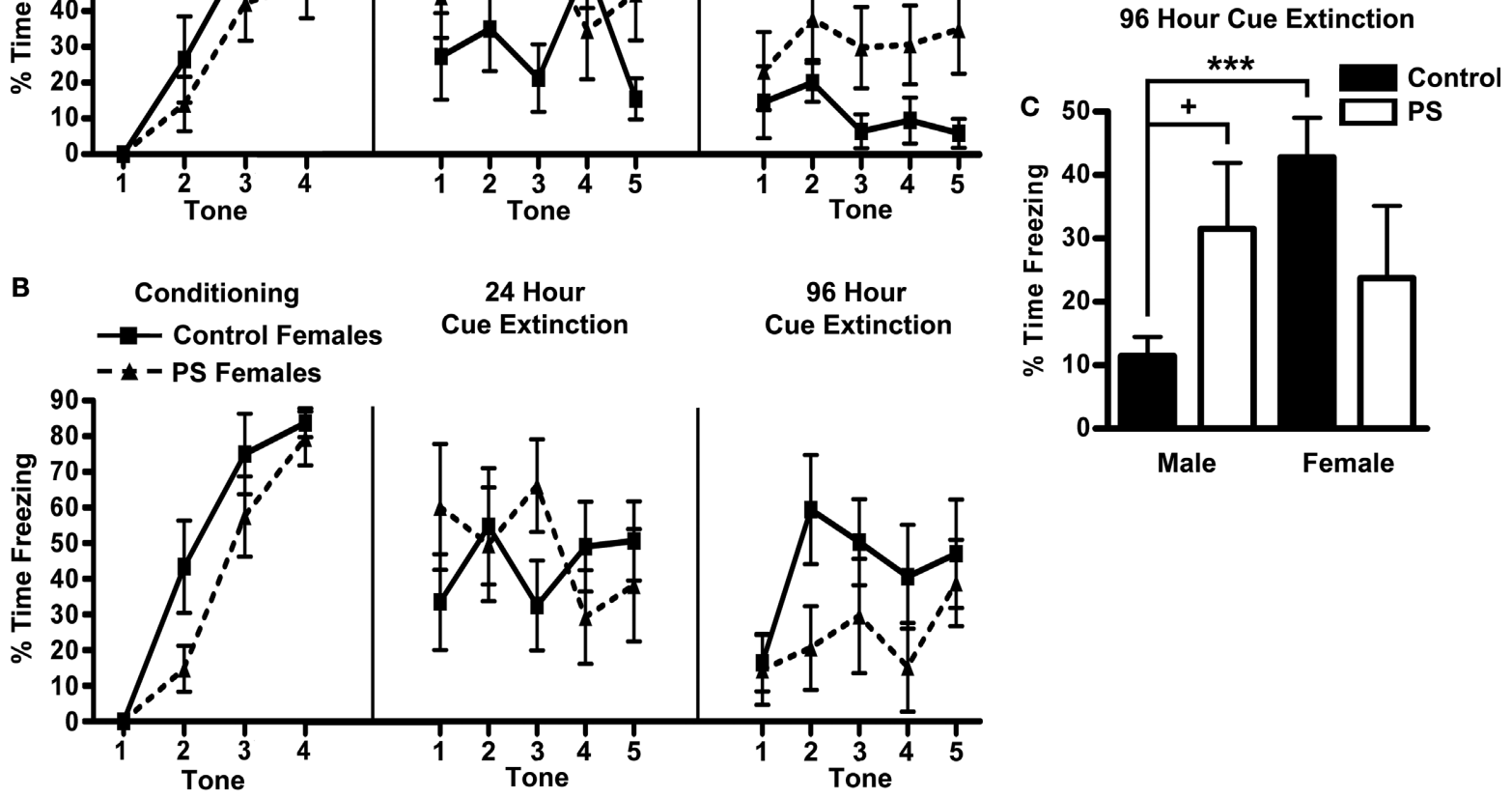

D 24 Hour Context Extinction

E 96 Hour Context Extinction
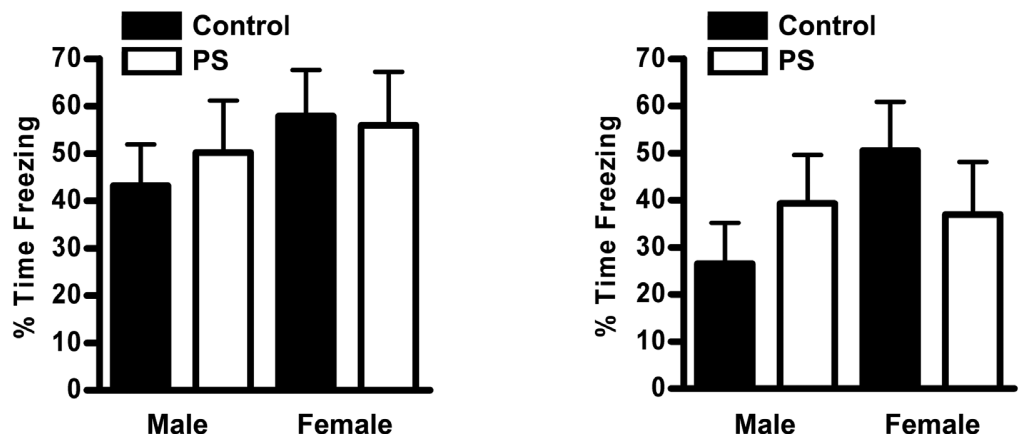

FIGURE 4 | Fear conditioning. Freezing in response to the tone during conditioning and cue extinction trials conducted 24 and $96 \mathrm{~h}$ later in male (A) and (B) female rats. Prenatal stress impaired the development of conditioned responses to the tone (treatment effect, $p<0.05$ ), and females tended to respond more than males (sex effect, $p<0.054$ ). Additionally, sex and treatment interacted $(p<0.03)$ to influence behavior on the $96 \mathrm{~h}$ cue extinction test $\mathbf{( C )}$; the ability to extinguish conditioned responses to the tone was impaired in prenatally stressed males $(+p<0.09)$ but not females, and prenatal stress eliminated the sex difference observed in control animals $\left({ }^{* *} p<0.0001\right)$. Context-dependent freezing was not influenced by either sex or treatment, during either the $24 \mathrm{~h}$ (D) or $96 \mathrm{~h}$ (E) trials. 
animals at the $96 \mathrm{~h}$ cue extinction trial, with females continuing to freeze at very high levels (control females $>$ control males $p<0.0001$ ); in contrast, prenatally stressed males and females froze at similar levels during this trial. Finally, context-dependent freezing did not differ significantly between sexes or treatment groups (Figures 4D,E).

\section{DISCRIMINATION MEMORY}

Because prenatal treatment and time of training were not found to interact for any measure, impact of these factors is illustrated separately. Separate $2 \times 2 \times 5$ repeated measures ANOVAs (treatment [prenatal stress vs. control], time of training [active vs. inactive], training day [days 1-5] were conducted for number of correct trials, reference memory errors, and working memory errors during training on each version of the test. For the retention tests, separate $2 \times 2$ ANOVAs (treatment, time of training) were conducted for the same three performance measures.

\section{Spatial/visual discrimination test}

Animals' performance improved with training, as evidenced by an increase in the number of correct trials $\left(F_{4,88}=22.1, p<0.0001\right)$, and concomitant reductions in the number of both reference $\left(F_{4,88}=27.9\right.$, $p<0.0001)$ and working $\left(F_{4,88}=14.7, p<0.0001\right)$ memory errors across training days. Animals exposed to prenatal stress committed significantly more working memory errors on this test $\left(F_{1,22}=5.5\right.$, $p<0.03$; Figure 5A). The treatment effect interacted with day of training $\left(F_{4,88}=5.3, p<0.001\right)$ such that the group difference was greatest on the first day of training (prenatal stress $>$ control, $p<0.01$ on day 1). There was also a trend for prenatally stressed animals to make more working memory errors than control rats on the two week retention test $\left(F_{1,22}=3.8, p<0.066\right.$; Figure 5B). Additionally, a significant negative Pearson product-moment correlation was found between working memory errors committed by prenatally stressed animals on the first day of training and the number of correct trials they made on the 2 -week retention test $(r=-0.72, p<0.01)$, whereas no such relationship was found among control animals (Figure 5C). Animals trained during the active phase of the light cycle had fewer correct trials $\left(F_{1,22} 4.7, p<0.05\right.$; Figure 5D) and made more reference memory errors $\left(F_{1,22}=10.8, p<0.01\right.$; Figure $\left.5 \mathrm{E}\right)$ during training on this task compared to those trained during the inactive phase. Time of training did not impact performance on the 2-week memory retention test (data not shown).

\section{Spatial discrimination test}

The number of correct trials increased across training days $\left(F_{4,88}=24.7, p<0.0001\right)$, while there was a concomitant reduction in the number of both reference $\left(F_{4,88}=39.3, p<0.0001\right)$ and

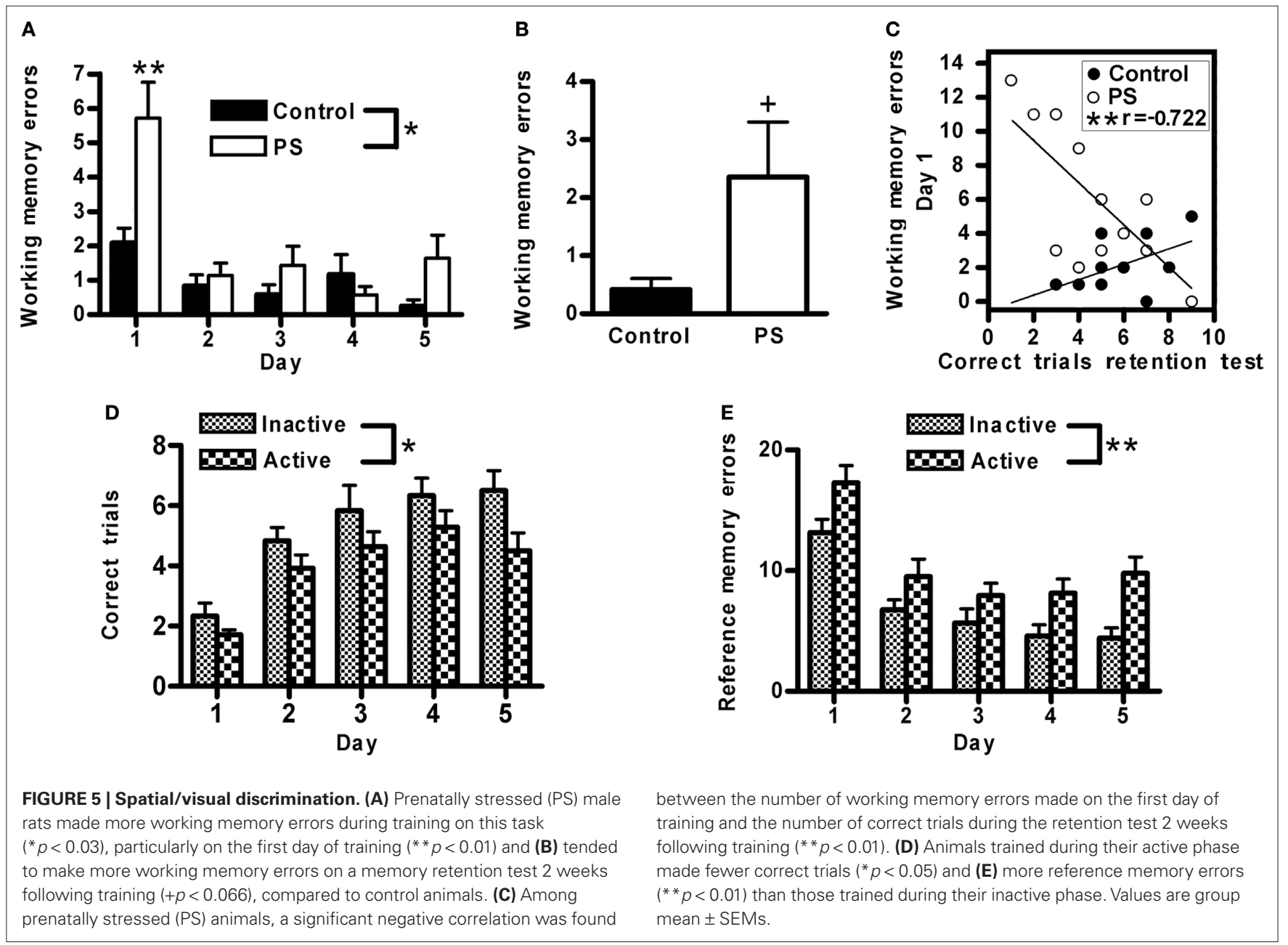


working $\left(F_{4,88}=7.9, p<0.0001\right)$ memory errors, indicating that animals' performance on this task improved with training. Prenatal stress treatment did not significantly impact any of the performance measures examined, nor did this factor interact with any other (data not shown). Animals trained during the active phase of the light cycle showed a trend toward committing more reference memory errors than animals trained during the inactive phase $\left(F_{1,22}=3.8\right.$, $p<0.065)$; this effect interacted with day of training $\left(F_{4,88}=3.0\right.$, $p<0.03$ ) such that the difference between active vs. inactive phase trained animals diminished over training $(p<0.02$ on first day of training; comparisons on other days not significant, Figure 6A). In the 2 -week retention test, animals trained during the active phase made fewer working memory errors than those trained during the inactive phase $\left(F_{1,22}=8.4, p<0.01\right.$; Figure 6B).

\section{Visual discrimination test}

The number of correct trials increased across training days $\left(F_{4,88}=18.9, p<0.0001\right)$, while there was a concomitant reduction in the number of both reference $\left(F_{4,88}=24.5, p<0.0001\right)$ and working $\left(F_{4,88}=11.4, p<0.0001\right)$ memory errors, indicating that animals' performance on this task improved with training. During training,
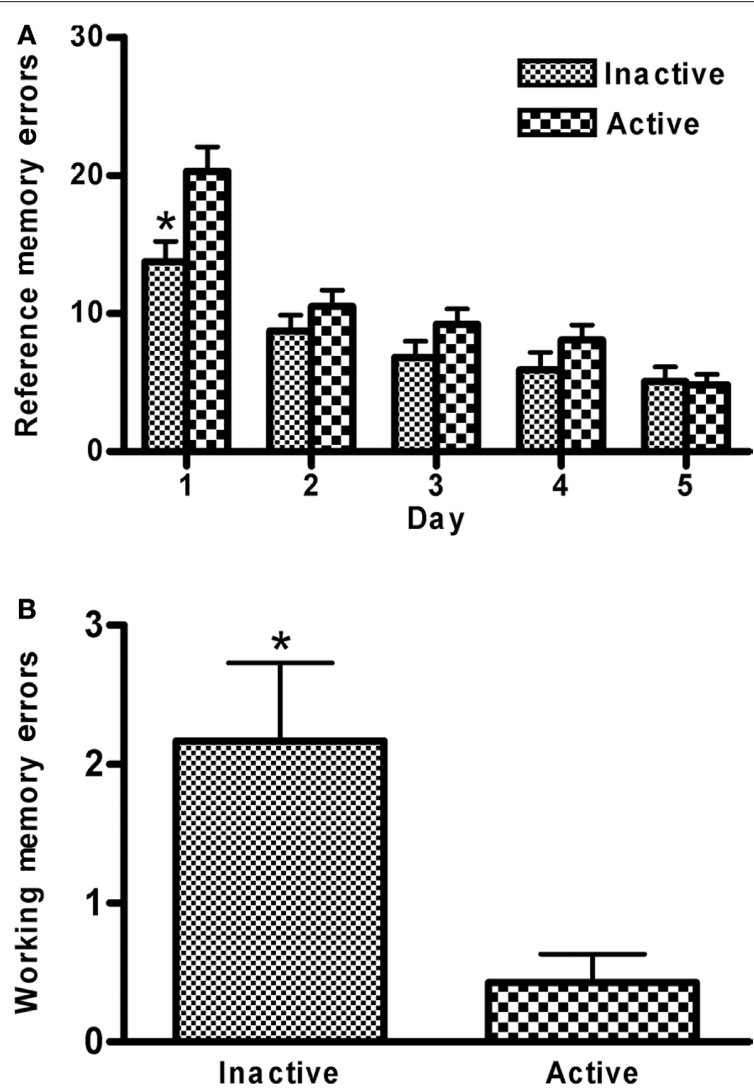

FIGURE 6 | Spatial discrimination. (A) Animals trained during their active phase made more reference memory errors on this task, especially on the first day of training, than animals trained during their inactive phase (phase $\times$ training interaction $p<0.03$; ${ }^{*} p<0.02$ ). (B) On a memory retention 2 weeks following training, animals traine tested during their active phase committed fewer working memory errors compared to animals trained and tested during their inactive phase $\left({ }^{*} p<0.02\right)$. Values are group mean \pm SEMs prenatal stress did not impact any of the performance measures examined for the training trials, nor did this factor interact with any other (data not shown). However, prenatally stressed rats made more working memory errors than controls on the 2-week retention test $\left(F_{1,22}=5.0, p<0.04\right.$; Figure 7A) (in fact, none of the control animals made a single working memory error during this test). Time of training did not significantly impact performance measures on the training trials or the 2-week retention test (data not shown). On the 2-month (final) retention test, prenatally stressed rats had fewer correct trials $\left(F_{1,20}=7.4, p<0.02\right.$; Figure $\left.7 \mathrm{~B}\right)$ and made more reference memory $\left(F_{1,20}=6.6, p<0.02\right.$; Figure 7C) and working memory errors $\left(F_{1,20}=4.3, p=0.05\right.$; Figure 7D) than control animals. (We were unable to include two animals in this analysis: one control/active period rat died prior to testing, and one control/inactive period rat remained immobile during more than half of the trials.) Time of training did not impact performance during training or on the 2 -week retention test; however, on the 2 -month retention test animals trained during the inactive phase of the light cycle made fewer correct trials $\left(F_{1,20}=13.5, p<0.01\right.$; Figure 7E), more reference memory errors $\left(F_{1,20}=7.6, p<0.02\right.$; Figure $7 \mathrm{~F}$ ) and trended toward making more working memory errors $\left(F_{1,20}=3.7, p<0.071\right.$; Figure 7G).

\section{DISCUSSION MAJOR FINDINGS}

Random variable prenatal stress during the third week of rat gestation induced deficits in object recognition memory, spatial reference memory, conditioned fear memory, and object discrimination memory, especially working memory for objects (findings summarized in Table 1). Specifically, adult males (but not females) exposed to prenatal stress failed to demonstrate competence on the novel object recognition memory task, which we report normally develops over adolescence. Reference memory for a spatial location was similarly impaired, with prenatally stressed males requiring significantly more time to locate the hidden platform compared to controls during training on the Morris water maze; additionally, a comparison of performance on the last day of training vs. performance on a recall test 4 days later showed evidence of impaired recall by prenatally stressed animals that was not exhibited by controls. Using iterative versions of the reward-motivated "Can Test” (Popovic et al., 2001), we determined that prenatal stress also significantly impairs working memory, as the number of working memory errors committed by prenatally stressed male rats was elevated during learning of a spatial/visual discrimination, as well as during recall of previously learned object discriminations. During learning, the performance deficit was specific to working memory, as the number of correct trials made and the number of reference memory errors made did not differ between control and prenatally stressed animals. Using this task we also determined that long-term memory was significantly disrupted by prenatal stress: in contrast to control animals, whose performance on all measures remained intact after a 2-month hiatus from behavioral testing, prenatally stressed male rats had fewer correct trials and made significantly more of both working and reference memory errors on the long-term retention test, indicating a profoundly reduced ability to recall a previously well-learned association between a particular object and a reward. In the aversive fear conditioning 


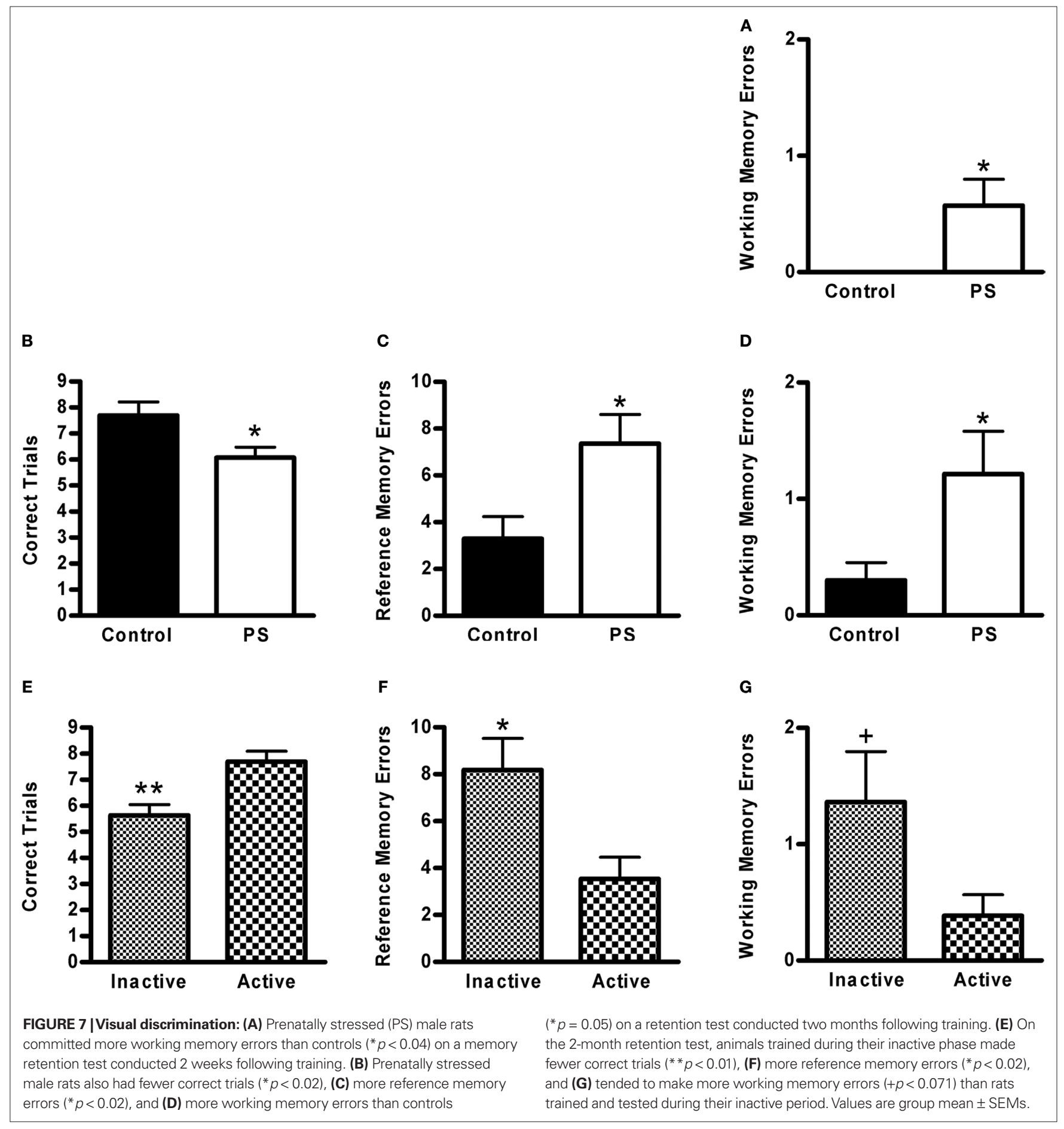

paradigm used, prenatally stressed animals showed a reduced ability to learn the predictive nature of a stimulus. Additionally, prenatally stressed males, in contrast to control males, maintained high levels of responding to the footshock-predictive stimulus across extinction trials, indicating a perseverative behavioral strategy (the performance of prenatally stressed females was indistinguishable from that of control females). The cognitive deficits we report here are subtle compared to what is observed following a brain lesion or genetic knockout, but considering that the prenatal stress paradigm is a non-invasive developmental manipulation (with a high degree of face validity) and that the deficits are pervasive, these findings are significant.

The deficits observed here may be due to exposure to elevated glucocorticoids during prenatal development. Maternal glucocorticoids readily cross the placenta and can interact with any fetal brain region expressing receptors (Zarrow et al., 1970), and we have previously shown that offspring do not develop abnormal phenotypes if the stress is administered during the second week of 
Table 1 | Summary of the cognitive deficits observed following exposure to repeated variable prenatal stress during the third week of rat gestation.

\begin{tabular}{lc}
\hline Test & Effect \\
\hline OBJECT RECOGNITION MEMORY & \\
Habituation: locomotor activity & $\uparrow$ \\
Introduction: encoding behaviors & - \\
Recognition memory & $\downarrow \neq$ \\
MORRIS WATER MAZE & \\
Habituation & - \\
Learning & $\downarrow$ \\
Retention (4-days) & $\downarrow$ \\
FEAR CONDITIONING & \\
Conditioning & $\downarrow$ \\
Cue extinction & $\downarrow \neq$ \\
Context extinction & - \\
DISCRIMINATION MEMORY & \\
Spatial/visual discrimination & \\
Learning: working memory & \\
Retention (2-week): working memory & \\
Spatial discrimination & \\
Learning & \\
Retention (2-week) & \\
Visual discrimination & \\
Learning & \\
Retention (2-week): working memory & \\
Retention (2-month): & Working memory \\
$\quad$ Reference memory & \\
$\quad$ Correct trials & \\
\hline & \\
\hline & \\
\hline
\end{tabular}

$\downarrow$ impaired or $\uparrow$ increased as a consequence of prenatal stress, $\neq$ effect observed in males but not females, -- no change.

gestation, prior to the expression of glucocorticoid receptors in the fetal brain (Koenig et al., 2005). Although differences in postnatal maternal care can also impact brain development of offspring, in our hands prenatally stressed dams don't exhibit detectable alterations in maternal care behaviors such as arched back nursing, time spent on the nest or grooming, and latency to pup retrieval (James I. Koenig, unpublished observations), and abnormal phenotypes observed in prenatally stressed pups are not rescued by crossfostering at birth to a non-stressed mother (Lee et al., 2007).

\section{PERFORMANCE DEFICITS REFLECT ALTERATIONS IN MNEMONIC PROCESSES}

Several of our findings support the notion that the performance deficits observed here for male rats exposed to prenatal stress reflect disruptions in actual mnemonic processes and not other factors, such as heightened anxiety or reduced motivation. For instance, in the object recognition memory paradigm, prenatal stress did not affect any measure of information collecting behavior during the introduction, including the amount of time spent investigating objects and the number of investigative bouts animals initiated with objects. This finding rules out the possibility that male rats experienced heightened novelty-associated anxiety induced by the objects which could have negatively impacted memory, or that prenatally stressed male rats couldn't remember the familiar object because they had interacted with it less during the introduction. Similarly, whereas prenatal stress impaired learning as well as recall of the location of the hidden escape platform on the Morris water maze, there were no differences in latency to initially discover the platform during habituation, and no performance differences at the outset of training, indicating similar levels of motivation to escape between prenatally stressed animals and controls, as well as similar gross motor abilities. Finally, the lack of an impact of prenatal stress on visual acuity is implied by the findings that (a) performance deficits on the object discrimination task were largely restricted to working memory, leaving reference memory for objects relatively spared, and (b) in the training trials on the spatial/ visual discrimination version of the task, deficits were restricted to the first day of training (rather than remaining constant over time as would be expected if vision were impaired).

\section{IMPACT OF PRENATAL STRESS ON COGNITIVE BRAIN REGIONS}

The pattern of cognitive deficits that we observed clearly suggests an impairment in hippocampus-supported mnemonic processes, including both spatial reference and working memory as tested using the Morris water maze and the spatial/visual discrimination version of the Can Test. While consistent with what has been observed in most studies conducted using other rodent gestational stress paradigms and species (Lordi et al., 1997; Lemaire et al., 2000; Gue et al., 2004; Meunier et al., 2004; Son et al., 2006; Yang et al., 2006; Mueller and Bale, 2007; Wu et al., 2007; Yaka et al., 2007), our findings of spatial memory deficits are the first to be reported following the rat repeated variable prenatal stress paradigm. Given that this paradigm generates distinct anxiogenic and neuroendocrine profiles from the repeated restraint paradigm (Richardson et al., 2006), the fact that spatial memory deficits are common to both speaks to the high sensitivity of the developing fetal hippocampus to elevations in maternal glucocorticoids. Our findings also provide an important confirmation that the spatial memory deficits persist into adulthood. Interestingly, contextual-dependent fear conditioning was unaffected by prenatal stress, suggesting that some selectivity may exist for the impact of prenatal stress on the hippocampus. Nevertheless, electrophysiological studies have confirmed hippocampal dysfunction as a consequence of prenatal stress, as NMDA-dependent hippocampal long-term potentiation (LTP) is impaired while hippocampal long-term depression (LTD) is enhanced in rodents exposed to gestational stress (Son et al., 2006; Yang et al., 2006; Yaka et al., 2007). Additionally, prenatal stress impairs hippocampal N40 sensory gating (Koenig et al., 2005), the rodent analog of P50 gating, disruption of which is commonly found among individuals with schizophrenia (Adler et al., 1998). Synaptic reductions in both NR1 and NR2B subunits of the NMDA receptor and the GluR1 subunit of the AMPA receptor have also been found in the hippocampus of these animals, with some variability in findings between studies that perhaps reflects speciesspecific mechanisms of prenatal stress (Son et al., 2006; Yaka et al., 2007). Additionally, hippocampal neurogenesis, which is known to be regulated by corticosterone levels postnatally (Gould et al., 1992), is also reduced across the lifespan as a consequence of prenatal exposure to stress in rats (Lemaire et al., 2000; Mandyam et al., 2008). Furthermore, the normal increase in neurogenesis 
that accompanies spatial learning in the Morris water maze is not observed in animals exposed to prenatal stress (Lemaire et al., 2000), suggesting either that prenatal stress blocks hippocampal neurogenesis which then prevents optimal spatial learning, or that prenatally stressed animals do not effectively learn this task and so fail to induce hippocampal neurogenesis - either way, collectively the literature indicates a profound, long-term impact of prenatal stress on hippocampal function, similar to what is observed in schizophrenia (reviewed by Boyer et al., 2007).

The present studies extend the implications of prenatal stress exposure for cognition beyond the hippocampus. The development of a conditioned fear memory, which we found to be disrupted by prenatal stress, is known to rely heavily on the amygdala (LeDoux, 2003). Additionally, extinction of discrete cue-associated conditioned fear memory, which we report is disrupted in male but not female rats exposed to prenatal stress, is highly dependent on the ventral medial prefrontal cortex as evidenced by both lesion studies (Morgan and LeDoux, 1995; Quirk et al., 2000) and electrophysiological work showing that firing of ventral medial prefrontal neurons is correlated with memory for fear extinction (Milad and Quirk, 2002). Both performance on this task and the morphology of prefrontal cortical neurons are affected by exposure to stress during adulthood (Cook and Wellman, 2004; Miracle et al., 2006; Radley et al., 2006). To our knowledge this is the first report that prenatal exposure to stress disrupts extinction of a cueconditioned fear memory. The prenatal stress-induced increase in working memory errors - observed in both the spatial/visual and visual alone versions of the Can Test - can be interpreted as perseverative behavior and also suggests that prefrontal development is disrupted as a consequence of prenatal stress. Such cognitive deficits may be related to our findings that prenatal stress disrupts the periadolescent maturation of medial prefrontal neurons and alters prefrontal expression of genes involved in synaptic plasticity (Kinnunen et al., 2003; Markham and Koenig, 2009), similar to what has been found in post-mortem tissue from schizophrenic individuals (e.g., Broadbelt et al., 2002; Beneyto and MeadorWoodruff, 2008). Another interesting parallel is the finding that more working memory errors committed by prenatally stressed rats on the first day of spatial/visual discrimination training was associated with their fewer number of correct trials on the 2-week retention test-similarly, Prentice et al. (2008) showed that the poor prefrontal-dependent performance of patients with schizophrenia could be predicted by their inability to use feedback on the first four card trials of the Wisconsin Card Sorting Task. More recently, this group has confirmed that patients with schizophrenia have reduced working memory capacity (Gold et al., 2010). A reduction in the capacity of working memory could account for the working memory deficits observed here following prenatal stress.

Our findings indicate that prenatal stress impairs memory for the visual features of objects, because prenatally stressed adult male rats were unable to discriminate the familiarity of previously encountered objects. The majority of lesion studies, including those which examine effects on the novel object recognition paradigm employed here, suggest that the hippocampus is not required for spontaneous object recognition memory (reviewed by Steckler et al., 1998a; Mumby, 2001; Ainge et al., 2006). Rather, non-spatial item recognition in rodents is supported primarily by cortical areas, especially the perirhinal cortex (Steckler et al., 1998a). To our knowledge the impact of prenatal stress on the perirhinal cortex has not been examined, although other cortical areas, including the prefrontal cortex, certainly show neuroanatomical and neurochemical disruptions that, if also characteristic of the perirhinal cortex, could modulate memory for objects (e.g., Steckler et al., 1998a,b; Weinstock, 2001; Bowman et al., 2004; Fumagalli et al., 2009; Markham and Koenig, 2009; Carboni et al., 2010).

\section{MALE-SPECIFIC VULNERABILITY TO PRENATAL STRESS}

While several groups have reported differential effects of prenatal stress in males and females, the present studies are unique in that they are the first to describe sex-specific deficits in cognitive abilities as a consequence of the repeated variable prenatal stress paradigm in rats. This is important because previous work makes it clear that the phenotypes impacted and whether males or females appear more vulnerable depends on the nature of the prenatal stress paradigm (Bowman et al., 2004; Richardson et al., 2006; Mueller and Bale, 2007; Mandyam et al., 2008; reviewed by Weinstock, 2007; Zuena et al., 2008). In the present studies, males were found to be more vulnerable to this environmental insult than females. Similar to what has previously been reported (Bowman et al., 2004), the ability of adult control males and females to recognize novel objects was essentially equivalent. However, prenatally stressed males failed to develop competent novel object recognition memory skills, whereas females' performance on this task was unaffected by prenatal stress. This indicates that repeated variable prenatal stress exerts a sexually dimorphic impact on object recognition memory that apparently does not result from the maternal repeated restraint stress paradigm (Bowman et al., 2004). It also indicates that interpretation of the prenatal stress effect as one of either masculinizing females or feminizing males may not be appropriate in every case - our findings demonstrate that sexually dimorphic responses to gestational stress can occur even for behaviors that do not normally differ between males and females. We also report that, while the development of a conditioned fear memory was impaired in prenatally stressed animals of both sexes, extinction of a cued fear memory was disrupted in male, but not female rats exposed to prenatal stress. In contrast to object recognition memory, fear memory extinction was found to be sexually dimorphic, with control males exhibiting robust extinction of the fear memory and control females maintaining high levels of responding to the tone in the absence of the footshock, consistent with what has previously been shown (Baran et al., 2009). Although not examined here, others' work indicates that sexual dimorphism in fear memory extinction depends on ovarian hormones in females, and that fear memory extinction fluctuates across the rat estrous cycle (Milad et al., 2009). In the present study, because prenatally stressed males did not extinguish freezing in response to the tone, and prenatally stressed females were unaffected on this measure, prenatal stress eliminated the normal sex difference on this task. Although females have been characterized on relatively fewer phenotypes to date following repeated variable prenatal stress, there is some precedent for the finding of greater male vulnerability in this paradigm. For instance, although both sexes show reduced social interaction as a consequence of prenatal stress, the magnitude of the effect is roughly twice as large in males compared to 
females (Markham et al., 2008). Additionally, prenatally stressed males show some behavioral abnormalities during place conditioning, whereas prenatally stressed females are indistinguishable from control females (Markham et al., 2009). Finally, sex-specific patterns of prefrontal pyramidal neuron maturation during adolescence are disrupted by prenatal stress in males but not females (Markham and Koenig, 2009).

The finding of greater male vulnerability to prenatal stress may be relevant to the etiology of schizophrenia, since prenatal stress has been linked to an increase in the illness and two meta-analyses have concluded that men are approximately $40 \%$ more likely to develop schizophrenia than women (Aleman et al., 2003; McGrath et al., 2004). It is unknown why men are more likely to develop the illness than women, but at least one epidemiological study suggests that a sex difference in the vulnerability to prenatal stress may be partially accountable (van Os and Selten, 1998). Because women have a later age of adolescent onset and a second, post-menopausal peak in incidence of this illness, it seems likely that estrogen raises the vulnerability threshold for development of schizophrenia (Hafner et al., 1998). Intriguingly, some recent evidence in mice suggests that sex differences in placental epigenetic machinery may underlie adult behavioral sex differences that emerge in response to prenatal stress (Mueller and Bale, 2008), indicating that sex-specific programming in response to environmental insults associated with schizophrenia begins very early in gestation.

\section{POST-ADOLESCENT EMERGENCE OF PRENATAL STRESS-INDUCED DEFICITS}

We report here for the first time that competence on the object recognition memory task develops over adolescence for both males and females; only adult animals could reliably perform this task above chance levels. Importantly, the prenatal stress-induced impairment in novel object recognition memory only became obvious following adolescence; prior to puberty prenatally stressed male rats were indistinguishable from controls. Both the periadolescent maturation of performance on this task and the male-specific, postadolescent emergence of prenatal stress-induced deficits may be related to the continued development of brain areas important for cognition (and disrupted in schizophrenia) over the periadolescent time frame. In particular, the prefrontal cortex has been shown to undergo sex-specific patterns of structural maturation during adolescence, at least some of which are altered by prenatal exposure to stress (Markham et al., 2007; Markham and Koenig, 2009). Such a developmental trajectory thus has the potential to "unmask" sexspecific vulnerability to a prenatal insult very late in development, as is hypothesized to occur in schizophrenia. Previously, we have

\section{REFERENCES}

Adler, L. E., Olincy, A., Waldo, M., Harris, J. G., Griffith, J., Stevens, K., Flach, K., Nagamoto, H., Bickford, P., Leonard, S., and Freedman, R. (1998). Schizophrenia, sensory gating, and nicotinic receptors. Schizophr. Bull. 24, 189-202.

Ainge, J.A., Heron-Maxwell, C., Theofilas, P., Wright, P., de Hoz, L., and Wood, E. R. (2006). The role of the hippocampus in object recognition in rats: examination of the influence of task parameters and lesion size. Behav. Brain Res. 167, 183-195.

Aleman, A., Kahn, R. S., and Selten, J. P. (2003). Sex differences in the risk of schizophrenia: evidence from metaanalysis. Arch. Gen. Psychiatry 60, 565-571.

Baran, S. E., Armstrong, C. E., Niren, D. C., Hanna, J. J., and Conrad, C. D. (2009). Chronic stress and sex differences on the recall of fear conditioning and

found that prenatal stress-induced hypersensitivity to amphetamine and deficits in social behavior, while present prior to puberty, are exaggerated after adolescence, at least among males (females have yet to be evaluated at both ages) (Koenig et al., 2005; Lee et al., 2007).

\section{SUMMARY}

The present experiments are the first characterization of global cognitive deficits that emerge as a consequence of repeated variable prenatal stress during the third week of rat gestation. Exposure to prenatal stress using this paradigm induced pervasive cognitive impairments in adult offspring, including in spontaneous novel object recognition memory, spatial reference memory, learning, and extinction of a conditioned fear memory, and object discrimination memory, especially working memory for objects, as well as a profound deficit in long-term memory. The profile of the cognitive deficits that we observed confirms the sensitivity of the hippocampus to prenatal stress exposure, and suggests that the development of the amygdala as well as cortical areas including the ventral medial prefrontal and the perirhinal cortices may also be disrupted as a consequence of prenatal stress. Although far less explored, especially beyond infancy, cognitive deficits have also been reported following gestational stress in humans (Laplante et al., 2004; Bergman et al., 2007; Entringer et al., 2009; Bergman et al., 2010; Davis and Sandman, 2010). Additionally, prenatal stress increases the risk for developing schizophrenia (reviewed by Koenig et al., 2002), a psychiatric illness that is characterized by pervasive but generally subtle cognitive deficits, similar to those found here in response to prenatal stress. Importantly, we found that males were more vulnerable to developing adverse cognitive outcomes as a consequence of prenatal stress, a finding that may be of etiological relevance given that men are $\sim 40 \%$ more likely to develop schizophrenia compared to women (Aleman et al., 2003; McGrath et al., 2004). It is unknown why men are more likely to develop schizophrenia than women, but a sex difference in the vulnerability to prenatal stress may be partially accountable (van Os and Selten, 1998). Preclinical work on this question as well as the mechanisms for prenatal stress-induced cognitive deficits more generally is limited and merits further investigation.

\section{ACKNOWLEDGMENTS}

The authors wish to thank Brooke Kanaskie for technical assistance. This research was supported by T32 MH067533 (Julie A. Markham), K12HD043489 (Julie A. Markham), MH73826 (James I. Koenig), and P50 MH082999 (Project 1 and Core 3 - James I. Koenig).

extinction. Neurobiol. Learn. Mem.91, 323-332.

Beneyto, M., and Meador-Woodruff, J. H. (2008). Lamina-specific abnormalities of NMDA receptor-associated postsynaptic protein transcripts in the prefrontal cortex in schizophrenia and bipolar disorder. Neuropsychopharmacology 33, 2175-2186.

Bergman, K., Sarkar, P., Glover, V., and O'Connor, T. G. (2010). Maternal prenatal cortisol and infant cogni- tive development: moderation by infant-mother attachment. Biol. Psychiatry 67, 1026-1032.

Bergman, K., Sarkar, P., O’Connor, T. G., Modi, N., and Glover, V. (2007). Maternal stress during pregnancy predicts cognitive ability and fearfulness in infancy. J. Am. Acad. Child Adolesc. Psychiatry 46, 1454-1463.

Bowman, R. E., MacLusky, N. J., Sarmiento, Y., Frankfurt, M., Gordon, M., and Luine, V. N. (2004). Sexually 
dimorphic effects of prenatal stress on cognition, hormonal responses, and central neurotransmitters. Endocrinology 145, 3778-3787.

Boyer, P., Phillips, J. L., Rousseau, F. L., and Ilivitsky, S. (2007). Hippocampal abnormalities and memory deficits: new evidence of a strong pathophysiological link in schizophrenia. Brain Res. Rev. 54, 92-112.

Broadbelt, K., Byne, W., and Jones, L. B. (2002). Evidence for a decrease in basilar dendrites of pyramidal cells in schizophrenic medial prefrontal cortex. Schizophr. Res. 58, 75-81.

Buchanan, R. W., and Carpenter, W. T. (1994). Domains of psychopathology: an approach to the reduction of heterogeneity in schizophrenia. $J$. Nerv. Ment. Dis. 182, 193-204.

Buitelaar, J. K., Huizink, A. C., Mulder, E. J., de Medina, P. G., and Visser, G. H. (2003). Prenatal stress and cognitive development and temperament in infants. Neurobiol. Aging 24(Suppl 1), S53-S60; discussion S67-S68.

Carboni, E., Barros, V. G., Ibba, M., Silvagni, A., Mura, C., and Antonelli, M. C. (2010). Prenatal restraint stress: an in vivo microdialysis study on catecholamine release in the rat prefrontal cortex. Neuroscience 168, 156-166.

Cook, S. C., and Wellman, C. L. (2004). Chronic stress alters dendritic morphology in rat medial prefrontal cortex. J. Neurobiol. 60, 236-248.

Davis, E. P., and Sandman, C. A. (2010). The timing of prenatal exposure to maternal cortisol and psychosocial stress is associated with human infant cognitive development. Child Dev. 81, 131-148.

Entringer, S., Buss, C., Kumsta, R., Hellhammer, D. H., Wadhwa, P. D., and Wust, S. (2009). Prenatal psychosocial stress exposure is associated with subsequent working memory performance in young women. Behav. Neurosci. 123, 886-893.

Fumagalli, F., Pasini, M., Frasca, A., Drago, F., Racagni, G., and Riva, M. A. (2009). Prenatal stress alters glutamatergic system responsiveness in adult rat prefrontal cortex. J. Neurochem. 109, 1733-1744.

Gold, J. M., Hahn, B., Zhang, W. W., Robinson, B. M., Kappenman, E. S., Beck, V. M., and Luck, S. J. (2010). Reduced capacity but spared precision and maintenance of working memory representations in schizophrenia. Arch. Gen. Psychiatry 67, 570-577.

Goldman-Rakic, P. S. (1994). Working memory dysfunction in schizophrenia. J. Neuropsychiatry Clin. Neurosci. 6, 348-357.

Gould, E., Cameron, H. A., Daniels, D. C., Woolley, C. S., and McEwen, B. S. (1992). Adrenal hormones suppress cell division in the adult rat dentate gyrus. J. Neurosci. 12, 3642-3650.

Green, M. F. (1996). What are the functional consequences of neurocognitive deficits in schizophrenia? Am. J. Psychiatry 153, 321-330.

Gue, M., Bravard, A., Meunier, J., Veyrier, R., Gaillet, S., Recasens, M., and Maurice, T. (2004). Sex differences in learning deficits induced by prenatal stress in juvenile rats. Behav. Brain Res. 150, 149-157.

Hafner, H., an der Heiden, W., Behrens, S., Gattaz, W. F., Hambrecht, M., Loffler, W., Maurer, K., Munk-Jorgensen, P., Nowotny, B., Riecher-Rossler, A., and Stein, A. (1998). Causes and consequences of the gender difference in age at onset of schizophrenia. Schizophr. Bull. 24, 99-113.

Holson, R. R., and Pearce, B. (1992). Principles and pitfalls in the analysis of prenatal treatment effects in multiparous species. Neurotoxicol. Teratol. 14, 221-228.

Khashan, A.S., Abel, K. M., McNamee, R., Pedersen, M. G., Webb, R. T., Baker, P. N., Kenny, L. C., and Mortensen, P. B. (2008). Higher risk of offspring schizophrenia following antenatal maternal exposure to severe adverse life events. Arch. Gen. Psychiatry 65, 146-152.

Kinnunen, A. K., Koenig, J. I., and Bilbe, G. (2003). Repeated variable prenatal stress alters pre- and postsynaptic gene expression in the rat frontal pole. J. Neurochem. 86, 736-748.

Koenig, J. I., Elmer, G. I., Shepard, P. D., Lee, P. R., Mayo, C., Joy, B., Hercher, E., and Brady, D. L. (2005). Prenatal exposure to a repeated variable stress paradigm elicits behavioral and neuroendocrinological changes in the adult offspring: potential relevance to schizophrenia. Behav. Brain Res. 156, 251-261.

Koenig, J. I., Kirkpatrick, B., and Lee, P. (2002). Glucocorticoid hormones and early brain development in schizophrenia. Neuropsychopharmacology 27, 309-318.

Laplante, D. P., Barr, R. G., Brunet, A., Galbaud du Fort, G., Meaney, M. L., Saucier, J. F., Zelazo, P. R., and King, S. (2004). Stress during pregnancy affects general intellectual and language functioning in human toddlers. Pediatr. Res. 56, 400-410.

LeDoux, J. (2003). The emotional brain, fear, and the amygdala. Cell. Mol. Neurobiol. 23, 727-738.

Lee, P. R., Brady, D. L., Shapiro, R. A., Dorsa, D. M., and Koenig, J. I. (2007). Prenatal stress generates deficits in rat social behavior: Reversal by oxytocin. Brain Res. 1156, 152-167.

Lemaire, V., Koehl, M., Le Moal, M., and Abrous, D. N. (2000). Prenatal stress produces learning deficits associated with an inhibition of neurogenesis in the hippocampus. Proc. Natl. Acad. Sci. U.S.A. 97, 11032-11037.

Lordi, B., Protais, P., Mellier, D., and Caston, J. (1997). Acute stress in pregnant rats: effects on growth rate, learning, and memory capabilities of the offspring. Physiol. Behav. 62 , 1087-1092.

Mandyam, C. D., Crawford, E. F., Eisch, A. J., Rivier, C. L., and Richardson, H. N. (2008). Stress experienced in utero reduces sexual dichotomies in neurogenesis, microenvironment, and cell death in the adult rat hippocampus. Dev. Neurobiol. 68, 575-589.

Markham, J. A., and Koenig, J. I. (2009). Prefrontal neuronal architecture is disrupted in the rat prenatal stress model of schizophrenia. Schizophr. Bull. 35, 137.

Markham, J. A., Morris, J. R., and Juraska, J.M. (2007). Neuron number decreases in the rat ventral, but not dorsal, medial prefrontal cortex between adolescence and adulthood. Neuroscience 144, 961-968.

Markham, J.A., Mullins, S. E., and Koenig, J. I. (2009). Peri-adolescent maturation of object recognition memory and associative memory is disrupted in male, but not female, rats exposed to prenatal stress. Soc. Neurosci. Abstr. 341.26

Markham, J. A., Taylor, A., Shelton, S., Brady-Bell, D., and Koenig, J. I. (2008). The repeated variable prenatal stress paradigm as a rodent model for schizophrenia. American Neuroendocrine Society Workshop on the Neurobiology of Stress Abstracts, No. 23 .

McGrath, J., Saha, S., Welham, J., El Saadi, O., MacCauley, C., and Chant, D. (2004). A systematic review of the incidence of schizophrenia: the distribution of rates and the influence of sex, urbanicity, migrant status and methodology. BMC Med. 2, 13.

Meunier, J., Gue, M., Recasens, M., and Maurice, T. (2004). Attenuation by a sigmal (sigma1) receptor agonist of the learning and memory deficits induced by a prenatal restraint stress in juvenile rats. Br. J. Pharmacol. 142, 689-700.

Milad, M. R., Igoe, S. A., Lebron-Milad, K., and Novales, J. E. (2009). Estrous cycle phase and gonadal hormones influence conditioned fear extinction. Neuroscience 164, 887-895.

Milad, M. R., and Quirk, G. J. (2002). Neurons in medial prefrontal cortex signal memory for fear extinction. Nature 420, 70-74.

Miracle, A. D., Brace, M. F., Huyck, K. D., Singler, S. A., and Wellman, C. L. (2006). Chronic stress impairs recall of extinction of conditioned fear. Neurobiol Learn Mem 85, 213-218.
Morgan, M. A., and LeDoux, J. E. (1995). Differential contribution of dorsal and ventral medial prefrontal cortex to the acquisition and extinction of conditioned fear in rats. Behav. Neurosci. 109, 681-688.

Mueller, B. R., and Bale, T. L. (2007). Early prenatal stress impact on coping strategies and learning performance is sex dependent. Physiol. Behav. 91, 55-65.

Mueller, B. R., and Bale, T. L. (2008). Sexspecific programming of offspring emotionality after stress early in pregnancy. J. Neurosci. 28, 9055-9065.

Mumby, D. G. (2001). Perspectives on object-recognition memory following hippocampal damage: lessons from studies in rats. Behav. Brain Res. 127, 159-181.

Popovic, M., Biessels, G. J., Isaacson, R. L., and Gispen, W. H. (2001). Learning and memory in streptozotocin-induced diabetic rats in a novel spatial/ object discrimination task. Behav. Brain Res. 122, 201-207.

Prentice, K. J., Gold, J.M., and Buchanan, R. W. (2008). The Wisconsin Card Sorting impairment in schizophrenia is evident in the first four trials. Schizophr. Res. 106, 81-87.

Quirk, G. J., Russo, G. K., Barron, J. L., and Lebron, K. (2000). The role of ventromedial prefrontal cortex in the recovery of extinguished fear. $J$. Neurosci. 20, 6225-6231.

Radley, J. J., Rocher, A. B., Miller, M., Janssen, W. G., Liston, C., Hof, P. R., McEwen, B. S., and Morrison, J. H. (2006). Repeated stress induces dendritic spine loss in the rat medial prefrontal cortex. Cereb. Cortex 16, 313-320.

Richardson, H. N., Zorrilla, E. P., Mandyam, C. D., and Rivier, C. L. (2006). Exposure to repetitive versus varied stress during prenatal development generates two distinct anxiogenic and neuroendocrine profiles in adulthood. Endocrinology 147 , 2506-2517.

Son, G. H., Geum, D., Chung, S., Kim, E. J., Jo, J. H., Kim, C. M., Lee, K. H., Kim, H., Choi, S., Kim, H. T., Lee, C. J., and Kim, K. (2006). Maternal stress produces learning deficits associated with impairment of NMDA receptor-mediated synaptic plasticity. J. Neurosci. 26, 3309-3318.

Steckler, T., Drinkenburg, W. H., Sahgal, A., and Aggleton, J. P. (1998a). Recognition memory in rats - II. Neuroanatomical substrates. Prog. Neurobiol. 54, 313-332.

Steckler, T., Sahgal, A., Aggleton, J. P., and Drinkenburg, W. H. (1998b). Recognition memory in rats - III. Neurochemical substrates. Prog. Neurobiol. 54, 333-348. 
van Os, J., and Selten, J. P. (1998). Prenatal exposure to maternal stress and subsequent schizophrenia. The May 1940 invasion of The Netherlands. Br. J. Psychiatry 172, 324-326.

Weinstock, M. (2001). Alterations induced by gestational stress in brain morphology and behaviour of the offspring. Prog. Neurobiol. 65, 427-451.

Weinstock, M. (2007). Gender differences in the effects of prenatal stress on brain development and behaviour. Neurochem. Res. 32, 1730-1740.

Weinstock,M.(2008). Thelong-term behavioural consequences of prenatal stress. Neurosci. Biobehav. Rev. 32, 1073-1086.

Wu, J., Song, T. B., Li, Y. J., He, K. S., Ge, L., and Wang, L. R. (2007). Prenatal restraint stress impairs learning and memory and hippocampal PKCbetal expression and translocation in offspring rats. Brain Res. 1141, 205-213.

Yaka, R., Salomon, S., Matzner, H., and Weinstock, M. (2007). Effect of varied gestational stress on acquisition of spatial memory, hippocampal LTP and synaptic proteins in juvenile male rats. Behav. Brain Res. 179, 126-132.

Yang, J., Han, H., Cao, J., Li, L., and Xu, L. (2006). Prenatal stress modifies hippocampal synaptic plasticity and spatial learning in young rat offspring. Hippocampus 16, 431-436.

Zarrow, M. X., Philpott, J. E., and Denenberg, V. H. (1970). Passage of 14C-4-corticosterone from the rat mother to the foetus and neonate. Nature 226, 1058-1059.

Zuena,A.R.,Mairesse,J.,Casolini,P.,Cinque, C., Alema, G. S., Morley-Fletcher, S., Chiodi, V., Spagnoli, L. G., Gradini, R., Catalani, A., Nicoletti, F., and Maccari, S. (2008). Prenatal restraint stress generates two distinct behavioral and neurochemical profiles in male and female rats. PLoS One 3, e2170. doi: 10.1371/ journal.pone.0002170.

Conflict of Interest Statement: The authors declare that the research was conducted in the absence of any commercial or financial relationships that could be construed as a potential conflict of interest.
Received: 09 August 2010; accepted: 24 October 2010; published online: 25 November 2010.

Citation: Markham JA, Taylor AR, Taylor SB, Bell DB and Koenig JI (2010) Characterization of the cognitive impairments induced by prenatal exposure to stress in the rat. Front. Behav. Neurosci. 4:173. doi: 10.3389/ fnbeh.2010.00173

Copyright (C) 2010 Markham, Taylor, Taylor, Bell and Koenig. This is an openaccess article subject to an exclusive license agreement between the authors and the Frontiers Research Foundation, which permits unrestricted use, distribution, and reproduction in any medium, provided the original authors and source are credited. 